Pacific Journal of Mathematics

RADII OF CONVEXITY FOR CERTAIN CLASSES OF 


\title{
RADII OF CONVEXITY FOR CERTAIN CLASSES OF UNIVALENT ANALYTIC FUNCTIONS
}

\author{
O. P. Juneja AND M. L. Mogra
}

Let $P(\alpha, \beta)$ denote the class of functions $p(z)=1+b_{1} z+\cdots$ which are analytic and satisfy the inequality $|(p(z)-1)|$ $\{2 \beta(p(z)-\alpha)-(p(z)-1)\} \mid<1$ for some $\alpha, \beta(0 \leqq \alpha<1,0<\beta \leqq 1)$ and all $z \in E=\{z:|z|<1\}$. Also, let $P_{b}(\alpha, \beta)=\left\{p \in P(\alpha, \beta): p^{\prime}(0)=\right.$ $2 b \beta(1-\alpha), 0 \leqq b \leqq 1\}$. In the present paper, we determine sharp estimates for the radii of convexity for functions in the classes $R_{a}(\alpha, \beta)$ and $S_{a}^{*}(\alpha, \beta)$ where $R_{a}(\alpha, \beta)=\{f(z)=z+$ $\left.a \beta(1-\alpha) z^{2}+\cdots: f^{\prime} \in P_{a}(\alpha, \beta), 0 \leqq a \leqq 1\right\}, S_{a}^{*}(\alpha, \beta)=\{g(z)=z+$ $\left.2 a \beta(1-\alpha) z^{2}+\cdots: z g^{\prime} / g \in P_{a}(\alpha, \beta), 0 \leqq a \leqq 1\right\}$. The results thus obtained not only sharpen and generalize the various known results but also give rise to several new results.

1. Introduction. Let $P$ denote the class of functions

$$
p(z)=1+b_{1} z+b_{2} z^{2}+\cdots
$$

which are analytic and satisfy $\operatorname{Re}(p(z))>0$ for $z \in E \equiv\{z:|z|<1\}$. Considerable work has been done to study the various aspects of the above mentioned class (see e.g., [11], [12] and others). Some of these results have also been extended to the class $P(\alpha)$ of functions $p(z)$ which are analytic and satisfy $\operatorname{Re}(p(z))>\alpha, 0 \leqq \alpha<1$ for $z \in E$. If $p \in P(\alpha)$, it is easily seen that $\left|b_{1}\right| \leqq 2(1-\alpha)$. Further, we note that if $\tau=\exp \left\{-i \arg b_{1}\right\}$ then $p(\tau z)=1+\left|b_{1}\right| z+\cdots$ and so while studying $P(\alpha)$, there is no loss of generality if one takes the first coefficient $b_{1}$ in (1.1) to be nonnegative.

McCarty in [8] determined a lower bound on $\operatorname{Re} z p^{\prime}(z) / p(z)$ for functions $p(z)$ in the class $P_{b}(\alpha) \equiv\left\{p \in P(\alpha): p^{\prime}(0)=2 b(1-\alpha), 0 \leqq\right.$ $b \leqq 1$. He also applied the results obtained to determine the sharp estimates for the radii of convexity of the two classes $R_{a}(\alpha)$ and $S_{a}^{*}(\alpha)$ for each $a \in[0,1]$ and $\alpha \in[0,1)$ where

$$
R_{a}(\alpha)=\left\{f(z)=z+a(1-\alpha) z^{2}+\cdots: f^{\prime} \in P_{a}(\alpha)\right\}
$$

and

$$
S_{a}^{*}(\alpha)=\left\{g(z)=z+2 a(1-\alpha) z^{2}+\cdots: z g^{\prime} / g \in P_{a}(\alpha)\right\} .
$$

For still another class $R_{a}^{\prime}(\alpha)$ defined by $R_{a}^{\prime}(\alpha)=\{f(z)=z+a(1-$ $\left.\alpha) z^{2}+\cdots:\left|f^{\prime}(z)-1\right|<\alpha, 1 / 2<\alpha \leqq 1, z \in E\right\}$ Goel [4] determined the radius of convexity.

In the present paper, we propose an approach by which it is not only possible to have a unified study of the above mentioned 
classes but of various other classes as well. For this purpose we introduce the following classes:

$$
\begin{gathered}
P(\alpha, \beta)=\left\{p(z)=1+b_{1} z+\cdots: \mid(p(z)-1) /\{2 \beta(p(z)-\alpha)\right. \\
-(p(z)-1)\} \mid<1, \text { for } \alpha \in[0,1), \beta \in(0,1] \text { and } z \in E\} \\
P_{b}(\alpha, \beta)=\left\{p \in P(\alpha, \beta): p^{\prime}(0)=2 b \beta(1-\alpha), 0 \leqq b \leqq 1\right\} \\
R_{a}(\alpha, \beta)=\left\{f(z)=z+a \beta(1-\alpha) z^{2}+\cdots: f^{\prime} \in P_{a}(\alpha, \beta), 0 \leqq a \leqq 1\right\} \\
S_{a}^{*}(\alpha, \beta)=\left\{g(z)=z+2 a \beta(1-\alpha) z^{2}+\cdots: z g^{\prime} / g \in P_{a}(\alpha, \beta), 0 \leqq a \leqq 1\right\}
\end{gathered}
$$

and determine sharp estimates for the radii of convexity for functions in $R_{a}(\alpha, \beta)$ and $S_{a}^{*}(\alpha, \beta)$.

2. Preliminary lemmas. Let $B$ denote the class of analytic functions $w(z)$ in $E$ which satisfy the conditions $w(0)=0$ and $|w(z)|<$ 1 for $z \in E$. We require the following lemmas:

Lemma 1 [15]. If $w \in B$, then for $z \in E$

$$
\left|z w^{\prime}(z)-w(z)\right| \leqq \frac{|z|^{2}-|w(z)|^{2}}{1-|z|^{2}}
$$

Lemma 2. Let $w \in B$. Then we have

$$
\begin{gathered}
\operatorname{Re}\left\{\frac{z w^{\prime}(z)}{(1+s w(z))(1+t w(z))}\right\} \leqq-\frac{1}{(s-t)^{2}} \operatorname{Re}\left\{s p(z)+\frac{t}{p(z)}-s-t\right\} \\
+\frac{1}{(s-t)^{2}} \frac{r^{2}|s p(z)-t|^{2}-|1-p(z)|^{2}}{\left(1-r^{2}\right)|p(z)|}
\end{gathered}
$$

where $p(z)=(1+t w(z)) /(1+s w(z)),|z|=r$ and $-1 \leqq t<s \leqq 1$.

Using the estimate (2.1), the lemma follows easily. Hence we omit the proof.

Lemma 3. If $p(z)=(1+t w(z)) /(1+s w(z)), \quad w \in B$, then for each $b \in[0,1]$ and $s, t$ satisfying $-1 \leqq t<s \leqq 1, p(z)$ lies in the disc

$$
\Delta(z) \equiv\left\{\zeta:\left|\zeta-A_{b}\right| \leqq D_{b}\right\}
$$

where

$$
A_{b}=\frac{(1+b r)^{2}-s t r^{2}(b+r)^{2}}{(1+b r)^{2}-s^{2} r^{2}(b+r)^{2}} ; D_{b}=\frac{(s-t) r(b+r)(1+b r)}{(1+b r)^{2}-s^{2} r^{2}(b+r)^{2}}
$$

and $r=|z|<1$. 
Proof. Since $p(z)=(1+t w(z)) /(1+s w(z))$, we have

$$
w(z)=\frac{1-p(z)}{s p(z)-t}=-[b z+\cdots]=-z \phi(z)
$$

where $\phi$ is analytic and $|\phi(z)| \leqq 1$ for $z \in E$ with $\phi^{\prime}(0)=b$. Now, since $(\phi(z)-b) /(1-b \phi(z))$ is subordinate to $z$, it follows that $\phi(z)$ is subordinate to $(z+b) /(1+b z)$ and so

$$
\left|\frac{1-p(z)}{s p(z)-t}\right| \leqq|z| \frac{(|z|+b)}{(1+b|z|)} .
$$

Putting $p(z)=\xi+i \eta,(2.4)$ gives

$$
\left|\xi+i \eta-\frac{(1+b r)^{2}-s t r^{2}(b+r)^{2}}{(1+b r)^{2}-s^{2} r^{2}(b+r)^{2}}\right| \leqq \frac{(s-t) r(b+r)(1+b r)}{(1+b r)^{2}-s^{2} r^{2}(b+r)^{2}} .
$$

Hence the lemma.

LEMMA 4. If $p(z)=(1+t w(z)) /(1+s w(z)), w \in B$, then for $|z|=r, 0 \leqq r<1$, we have

$$
\operatorname{Re}\left\{k p(z)+\frac{t}{p(z)}\right\}-\frac{r^{2}|s p(z)-t|^{2}-|1-p(z)|^{2}}{\left(1-r^{2}\right)|p(z)|}
$$

$(2.5) \geqq\left[\begin{array}{ll}\frac{2}{1-r^{2}}\left[\sqrt{(1+t)\left(1-t r^{2}\right)\left(k\left(1-r^{2}\right)+1-s^{2} r^{2}\right)}-\left(1-s t r^{2}\right)\right] \\ W / W^{*} & \text { if } R_{b} \leqq R^{*} \\ \text { if } R_{b} \geqq R^{*}\end{array}\right.$ where

$$
\begin{aligned}
W= & t\left(k t+s^{2}\right) r^{4}+2 b t\left\{(k+s)+\left(k t+s^{2}\right)\right\} r^{3} \\
& +\left[b^{2}(1+t)\left\{(k+t)+\left(k t+s^{2}\right)\right\}+2 t(k+s)-(s-t)^{2} \mid r\right. \\
& +2 b\{(k+t)+t(k+s)\} r+(k+t),
\end{aligned}
$$

$$
W^{*}=\left\{1+r b(1+t)+t r^{2}\right\}\left\{1+r b(1+s)+s r^{2}\right\}
$$

and $R^{* 2}=(1+t)\left(1-t r^{2}\right) /\left(k\left(1-r^{2}\right)+1-s^{2} r^{2}\right), R_{b}=A_{b}-D_{b}$ where $A_{b}, D_{b}$ are defined as in Lemma 3 and $k \geqq s,-1 \leqq t<s \leqq 1$.

Proof. Let $|z|=r$, and $p(z)=A_{b}+\xi+i \eta \equiv \mathrm{Re}^{i \psi}$, then $-\pi / 2<$ $\psi<\pi / 2$. Denoting the left hand side of (2.5) by $U_{b}(\xi, \eta)$, we get

$$
\begin{gathered}
U_{b}(\xi, \eta)=k\left(A_{b}+\xi\right)+t\left(A_{b}+\xi\right) R^{-2}+\frac{1-s^{2} r^{2}}{1-r^{2}}\left[\left(\left(A_{b}+\xi\right)-A_{1}\right)^{2}\right. \\
\left.+\eta^{2}-D_{1}^{2}\right] R^{-1}
\end{gathered}
$$


and

$$
\frac{\partial U_{b}}{\partial \eta}=\eta R^{-4} V_{b}(\xi, \eta)
$$

where

$$
\begin{aligned}
V_{b}(\xi, \eta)=-2 t\left(A_{b}+\xi\right) & +\left(D_{1}^{2}+2 A_{1}\left(A_{b}+\xi\right)-A_{1}^{2}\right)\left(\frac{1-s^{2} r^{2}}{1-r^{2}}\right) R \\
& +\left(\frac{1-s^{2} r^{2}}{1-r^{2}}\right) R^{3} \\
=-2 t R \cos \psi+ & \left(D_{1}^{2}-A_{1}^{2}+2 A_{1} R \cos \psi\right)\left(\frac{1-s^{2} r^{2}}{1-r^{2}}\right) R \\
+ & \left(\frac{1-s^{2} r^{2}}{1-r^{2}}\right) R^{3} \equiv M_{b}(R, \psi)(\text { say }) .
\end{aligned}
$$

Since for fixed $r, 0 \leqq r<1, A_{b}-D_{b}$ decreases as $b$ increases over the interval $[0,1]$, it follows that $R \geqq R \cos \psi \geqq A_{b}-D_{b} \geqq A_{1}-D_{1}$. Thus, for all $b, 0 \leqq b \leqq 1$,

$$
\begin{aligned}
M_{b}(R, \psi) & \geqq R \cos \psi\left[-2 t+\left(D_{1}^{2}-A_{1}^{2}+2 A_{1} R \cos \psi+R^{2}\right)\left(\frac{1-s^{2} r^{2}}{1-r^{2}}\right)\right] \\
& \geqq 2 R \cos \psi\left[\left(\frac{1-s^{2} r^{2}}{1-r^{2}}\right)\left(A_{1}-D_{1}\right)^{2}-t\right]>0,
\end{aligned}
$$

for all $s, t$ satisfying $-1 \leqq t<s \leqq 1$. Thus $V_{b}(\xi, \eta) \equiv M_{b}(R, \psi)$ is positive for all points in the disc $\Delta(z)$. Now, (2.7) gives that, for every fixed $\xi, U_{b}(\xi, \eta)$ is increasing function of $\eta$ for positive $\eta$ and is a decreasing function of $\eta$ for negative $\eta$. Thus, the minimum of $U_{b}(\xi, \eta)$ inside the disc $\Delta$ is attained on the diameter forming part of the real axis. Setting $\eta=0$ in (2.6), we obtain

$$
\begin{aligned}
\min _{-1 \leqq \eta \leqq 1} U_{b}(\xi, \eta) \equiv N_{b}(R)=(k & \left.+\frac{1-s^{2} r^{2}}{1-r^{2}}\right) R+\frac{(1+t)\left(1-t r^{2}\right)}{\left(1-r^{2}\right)} R^{-1} \\
& -2 A_{1}\left(\frac{1-r^{2} s^{2}}{1-r^{2}}\right)
\end{aligned}
$$

where $R=A_{b}+\xi \in\left[A_{b}-D_{b}, A_{b}+D_{b}\right]$. Thus the absolute minimum of $N_{b}(R)$ in $(0, \infty)$ is attained at

$$
R^{*}=\left(\frac{(1+t)\left(1-t r^{2}\right)}{k\left(1-r^{2}\right)+1-s^{2} r^{2}}\right)^{1 / 2}
$$

and the value of this minimum is equal to 


$$
\begin{aligned}
N_{b}\left(R^{*}\right)=\frac{1}{1-r^{2}}[ & \sqrt{\left(k\left(1-r^{2}\right)+1-s^{2} r^{2}\right)(1+t)\left(1-t r^{2}\right)} \\
& \left.-\left(1-s t r^{2}\right)\right] .
\end{aligned}
$$

Since it is easily seen that $R^{*}<A_{1}+D_{1}$ and that $A_{b}+D_{b}$ is a decreasing function of $b$ for $0 \leqq b \leqq 1$, it follows that $R^{*}<A_{b}+D_{b}$ for $b \in[0,1]$; but $R^{*}$ is not always greater than $A_{b}-D_{b}$. In case $R^{*} \notin\left[A_{b}-D_{b}, A_{b}+D_{b}\right]$, it can be easily verified that $N_{b}(R)$ increases with $R$ in $\left[A_{b}-D_{b}, A_{b}+D_{b}\right]$. Thus the minimum of $N_{b}(R)$ on the segment $\left[A_{b}-D_{b}, A_{b}+D_{b}\right]$ is attained at $R_{b}=A_{b}-D_{b}$. The value of this minimum equals

$$
N_{b}\left(R_{b}\right) \equiv N_{b}\left(A_{b}-D_{b}\right)=W / W^{*},
$$

where $W$ and $W^{*}$ are given by $(2.5$; a) and $(2.5 ; \mathrm{b})$. Moreover $N_{b}\left(R^{*}\right)=N_{b}\left(R_{b}\right)$ for those values of $k, s$, and $t$ for which $R_{b}=R^{*}$. Hence the lemma.

3. The class $R_{a}(\alpha, \beta)$. Let $R(\alpha, \beta)$ be the class of functions $f(z)=z+a_{2} z^{2}+\cdots$ which are analytic and satisfy the inequality $\left|\left(f^{\prime}(z)-1\right) /\left\{2 \beta\left(f^{\prime}(z)-\alpha\right)-\left(f^{\prime}(z)-1\right)\right\}\right|<1$ for some $\alpha, \beta(0 \leqq \alpha<1$, $0<\beta \leqq 1$ ) and $z \in E$. One of the authors [9] has shown that for $f \in R(\alpha, \beta),\left|a_{2}\right| \leqq \beta(1-\alpha)$. Define

$$
R_{a}(\alpha, \beta)=\left\{f(z)=z+a \beta(1-\alpha) z^{2}+\cdots: f^{\prime} \in P_{a}(\alpha, \beta), 0 \leqq a \leqq 1\right\} .
$$

Now, we determine a sharp estimate for the radii of convexity for functions in $R_{a}(\alpha, \beta)$.

THEOREM 1. Let $f \in R_{a}(\alpha, \beta)$, then $f$ is convex in $|z|<r_{0}$ where $r_{0}$ is the smallest positive root of the equation

$$
\begin{aligned}
1+4 \alpha \beta a r & +\left(4 \alpha \beta^{2} a^{2}-2(1+\beta-3 \alpha \beta)\right) r^{2}+4 \beta(2 \alpha \beta-1) a r^{3} \\
& +(2 \beta-1)(2 \alpha \beta-1) r^{4}=0
\end{aligned}
$$

if $R_{a} \geqq R^{*}$ and

$$
r_{0}=\left[\left\{-\alpha \beta+\sqrt{\alpha\left(1-2 \alpha \beta+\alpha \beta^{2}\right)}\right\} /(1-2 \alpha \beta)\right]^{1 / 2}
$$

if $R_{a} \leqq R^{*}$ where

$$
R_{a}=\frac{1+2 \alpha \beta a r+(2 \alpha \beta-1) r^{2}}{1+2 \beta a r+(2 \beta-1) r^{2}}, R^{*}=\left(\frac{\alpha\left(1-(2 \alpha \beta-1) r^{2}\right)}{1-(2 \beta-1) r^{2}}\right)^{1 / 2}
$$

and $r=|z|<1$. The result is sharp for each $\alpha, \beta(0 \leqq \alpha<1,0<$ $\beta \leqq 1$ ) and $0 \leqq a \leqq 1$. 
Proof. Since $f \in R_{a}(\alpha, \beta)$, an application of Schwarz's lemma gives

$$
f^{\prime}(z)=\frac{1+(2 \alpha \beta-1) w(z)}{1+(2 \beta-1) w(z)}
$$

where $w \in B$. Logarithmic differentiation of (3.1) gives

(3.2) $1+z \frac{f^{\prime \prime}(z)}{f^{\prime}(z)}=1-2 \beta(1-\alpha)\left\{\frac{z w^{\prime}(z)}{(1+(2 \beta-1) w(z))(1+(2 \alpha \beta-1) w(z))}\right\}$.

Applying (2.2) with $s=2 \beta-1, t=2 \alpha \beta-1$ to (3.2), we get

$$
\begin{aligned}
\operatorname{Re}\{1 & \left.+z \frac{f^{\prime \prime}(z)}{f^{\prime}(z)}\right\} \geqq \frac{1}{2 \beta(1-\alpha)}\left[\operatorname{Re}\left\{(2 \beta-1) p(z)+\frac{2 \alpha \beta-1}{p(z)}\right\}\right. \\
& \left.-\frac{r^{2}|(2 \beta-1) p(z)+1-2 \alpha \beta|^{2}-|1-p(z)|^{2}}{\left(1-r^{2}\right)|p(z)|}\right]+\frac{1-2 \alpha \beta}{\beta(1-\alpha)}
\end{aligned}
$$

where $p(z)=(1+(2 \alpha \beta-1) w(z)) /(1+(2 \beta-1) w(z))$. An application of Lemma 4 with $k=s=2 \beta-1, t=2 \alpha \beta-1$ to (3.3) gives

(3.4) $\operatorname{Re}\left\{1+z \frac{f^{\prime \prime}(z)}{f^{\prime}(z)}\right\}$

$$
\geqq\left(\begin{array}{c}
\frac{1}{\beta(1-\alpha)\left(1-r^{2}\right)}\left[\sqrt{4 \alpha \beta^{2}\left(1-(2 \beta-1) r^{2}\right)\left(1+(1-2 \alpha \beta) r^{2}\right)}\right. \\
\left.-\left(1+(1-2 \alpha \beta)(2 \beta-1) r^{2}\right)+(1-2 \alpha \beta)\left(1-r^{2}\right)\right] \\
\text { if } R_{a} \leqq R^{*}, \\
1+4 \alpha \beta a r+\left(4 \alpha \beta^{2} a^{2}-2(1+\beta-3 \alpha \beta)\right) r^{2} \\
\frac{+4 \beta \times(2 \alpha \beta-1) a r^{3}+(2 \beta-1)(2 \alpha \beta-1) r^{4}}{\left(1+2 \beta a r+(2 \beta-1) r^{2}\right)\left(1+2 \alpha \beta a r+(2 \alpha \beta-1) r^{2}\right)} \\
\text { if } R_{a} \geqq R^{*}
\end{array}\right.
$$

where

$$
\begin{gathered}
R_{a}=\frac{1+2 \alpha \beta a r+(2 \alpha \beta-1) r^{2}}{1+2 \beta a r+(2 \beta-1) r^{2}}, R^{*}=\left(\frac{\alpha\left(1-(2 \alpha \beta-1) r^{2}\right)}{1-(2 \beta-1) r^{2}}\right)^{1 / 2}, \\
0 \leqq a \leqq 1 .
\end{gathered}
$$

Now the theorem follows easily from (3.4).

The function given by

$$
f^{\prime}(z)=\frac{1-2 \alpha \beta a z+(2 \alpha \beta-1) z^{2}}{1-2 \beta a z+(2 \beta-1) z^{2}} \text { if } R_{a} \geqq R^{*},
$$

and

$$
f^{\prime}(z)=\frac{1-2 \alpha \beta c z+(2 \alpha \beta-1) z^{2}}{1-2 \beta c z+(2 \beta-1) z^{2}} \text { if } R_{a} \leqq R^{*}
$$

where $c$ is determined by the relation 


$$
\frac{1-2 \alpha \beta c r+(2 \alpha \beta-1) r^{2}}{1-2 \beta c r+(2 \beta-1) r^{2}}=R^{*}=\sqrt{\frac{\alpha\left(1+(1-2 \alpha \beta) r^{2}\right)}{\left(1-(2 \beta-1) r^{2}\right)}}
$$

show that the results obtained in the theorem are sharp.

Putting $\beta=1$, in Theorem 1 , we get the following result due to McCarty [8].

CoRollary 1(a). Each $f \in R_{a}(\alpha)$ maps $|z|<r_{0}$ onto a convex region where $r_{0}$ is the smallest positive root of the equation

$$
1+4 \alpha a r+\left(6 \alpha-4+4 \alpha a^{2}\right) r^{2}+4(2 \alpha-1) a r^{3}+(2 \alpha-1) r^{4}=0
$$

if $R_{a} \geqq R^{*}$ and

$$
r_{0}=[\{-\alpha+\sqrt{\alpha(1-\alpha)}\} /(1-2 \alpha)]^{1 / 2}
$$

if $R_{a} \leqq R^{*}$, where

$$
R_{a}=\frac{1+2 \alpha a r+(2 \alpha-1) r^{2}}{1+2 a r+r^{2}}, \quad R^{*}=\left(\frac{\alpha\left(1-(2 \alpha-1) r^{2}\right)}{1-r^{2}}\right)^{1 / 2}
$$

and $r=|z|<1$. The result is sharp for each $\alpha(0 \leqq \alpha<1)$ and $0 \leqq a \leqq 1$.

Corollary 1(b). Let $f \in R_{a}^{\prime}(\alpha)$, then $f$ is convex in $|z|<r_{0}$ where $r_{0}$ is the smallest positive root of the equation

$$
1+2(1-\alpha) a r+\left((1-\alpha) a^{2}-3 \alpha\right) r^{2}-2 \alpha a r^{3}=0
$$

if $R_{a} \geqq R^{*}$ and

$$
r_{0}=[\{-(1-\alpha)+\sqrt{(1-\alpha)(1+3 \alpha)}\} / 2 \alpha]^{1 / 2}
$$

if $R_{a} \leqq R^{*}$, where

$$
R_{a}=\frac{1+(1-\alpha) a r-\alpha r^{2}}{1+a r}, \quad R^{*}=\left[(1-\alpha)\left(1+\alpha r^{2}\right)\right]^{1 / 2}
$$

and $r=|z|<1$. The result is sharp for each $\alpha(0 \leqq \alpha<1)$ and $0 \leqq a \leqq 1$.

The result is obtained by replacing $\alpha$ by $1-\alpha$ and $\beta$ by $1 / 2$ in Theorem 1. It may be noted that this result was obtained by Goel [4] under the additional restriction $1 / 2 \leqq \alpha \leqq 1$.

REMARK. Replacing $(\alpha, \beta)$ by $(0,1)$, or by $(0,1-\delta), 0 \leqq \delta<1$ or by $(0,(2 \delta-1) / 2 \delta), 1 / 2<\delta \leqq 1$, or by $((1-\gamma) / 1+\gamma,(1+\gamma(/ 2), 0<$ $\gamma \leqq 1$, or by $((1-\delta+2 \gamma \delta) /(1+\delta),(1+\delta) / 2), 0 \leqq \gamma<1,0<\delta \leqq 1$, we get the estimates for the radii of convexity for functions with 
fixed second coefficient of the classes introduced and studied by MacGregor [7], Shaffer [13], Goel [3], Caplinger and Causey [1] and the authors [6] respectively.

4. The class $S_{a}^{*}(\alpha, \beta)$. Let $S^{*}(\alpha, \beta)$ be the class of functions $g(z)=z+a_{2} z^{2}+\cdots$ which are analytic and satisfy the inequality $\left|\left(z g^{\prime}(z) / g(z)-1\right) /\left\{2 \beta\left(z g^{\prime}(z) / g(z)-\alpha\right)-\left(z g^{\prime}(z) / g(z)-1\right)\right\}\right|<1$, for some $\alpha, \beta(0 \leqq \alpha<1,0<\beta \leqq 1)$ and $z \in E$. The authors [5] have shown that for $g \in S^{*}(\alpha, \beta),\left|a_{2}\right| \leqq 2 \beta(1-\alpha)$. Define

$$
S_{a}^{*}(\alpha, \beta)=\left\{g(z)=z+2 a \beta(1-\alpha) z^{2}+\cdots: z g^{\prime} / g \in P_{a}(\alpha, \beta), 0 \leqq \alpha \leqq 1\right\} .
$$

Now, we determine a sharp estimate for the radii of convexity for functions in $S_{a}^{*}(\alpha, \beta)$.

THEOREM 2. Let $g \in S_{a}^{*}(\alpha, \beta)$, then $g$ is convex in $|z|<r_{0}$ where $r_{0}$ is the smallest positive root of the equation

$$
\begin{aligned}
1+2 \beta(3 \alpha-1) a r & +\left(4 \alpha^{2} \beta^{2} \alpha^{2}+8 \alpha \beta-2-4 \beta\right) r^{2} \\
& -2 \beta\left(1+\alpha-4 \beta \alpha^{2}\right) a r^{3}+(1-2 \alpha \beta)^{2} r^{4}=0
\end{aligned}
$$

if $R_{a} \geqq R^{*}$ and

$$
r_{0}=\left[(5 \alpha-1) /\left\{\left(1-\alpha+4 \beta \alpha^{2}\right)+4 \alpha \sqrt{\left.\left(1+\beta-3 \alpha \beta+\alpha^{2} \beta^{2}\right)\right\}}\right]^{1 / 2}\right.
$$

if $R_{a} \leqq R^{*}$, where

$$
R_{a}=\frac{1+2 \alpha \beta a r+(2 \alpha \beta-1) r^{2}}{1+2 \beta a r+(2 \beta-1) r^{2}}, \quad R^{*}=\left(\frac{\alpha\left(1+(1-2 \alpha \beta) r^{2}\right)}{(2-\alpha)-(2 \beta-\alpha) r^{2}}\right)^{1 / 2}
$$

and $r=|z|<1$. The result is sharp for each $\alpha, \beta(0 \leqq \alpha<1,0<$ $\beta \leqq 1)$ and $0 \leqq a \leqq 1$.

Proof. Since $g \in S_{a}^{*}(\alpha, \beta)$, an application of Schwarz's lemma gives

$$
z \frac{g^{\prime}(z)}{g(z)}=\frac{1+(2 \alpha \beta-1) w(z)}{1+(2 \beta-1) w(z)}
$$

where $w \in B$. Logarithmic differentiation of (4.1) gives

$$
\begin{aligned}
1 & +z \frac{g^{\prime \prime}(z)}{g^{\prime}(z)}=\frac{1+(2 \alpha \beta-1) w(z)}{1+(2 \beta-1) w(z)} \\
& -2 \beta(1-\alpha)\left\{\frac{z w^{\prime}(z)}{(1+(2 \beta-1) w(z))(1+(2 \alpha \beta-1) w(z))}\right\} .
\end{aligned}
$$

Applying (2.2) with $s=2 \beta-1, t=2 \alpha \beta-1$ to (4.2), we get 


$$
\begin{aligned}
\operatorname{Re}\{1 & \left.+z \frac{g^{\prime \prime}(z)}{g^{\prime}(z)}\right\} \geqq \frac{1}{2 \beta(1-\alpha)}[\operatorname{Re}\{(4 \beta-1-2 \alpha \beta) p(z) \\
& \left.\left.+\frac{2 \alpha \beta-1}{p(z)}\right\}-\frac{r^{2}|(2 \beta-1) p(z)+1-2 \alpha \beta|^{2}-|1-p(z)|^{2}}{\left(1-r^{2}\right)|p(z)|}\right] \\
& +\frac{\alpha+\alpha \beta-1}{\beta(1-\alpha)}
\end{aligned}
$$

where $p(z)=(1+(2 \alpha \beta-1) w(z)) /(1+(2 \beta-1) w(z))$. Now, an application of Lemma 4 with $k=4 \beta-1-2 \alpha \beta, s=2 \beta-1$ and $t=2 \alpha \beta-1$ to (4.3) gives the required results easily.

The functions given by

$$
z \frac{g^{\prime}(z)}{g(z)}=\frac{1-2 \alpha \beta a z+(2 \alpha \beta-1) z^{2}}{1-2 \beta a z+(2 \beta-1) z^{2}} \text { if } R_{a} \geqq R^{*}
$$

and

$$
z \frac{g^{\prime}(z)}{g(z)}=\frac{1-2 \alpha \beta c z+(2 \alpha \beta-1) z^{2}}{1-2 \beta c z+(2 \beta-1) z^{2}} \text { if } R_{a} \leqq R^{*}
$$

where $c$ is determined by the relation

$$
\frac{1-2 \alpha \beta c r+(2 \alpha \beta-1) r^{2}}{1-2 \beta c r+(2 \beta-1) r^{2}}=R^{*}=\left(\frac{\alpha(1-(2 \alpha \beta-1)) r^{2}}{(2-\alpha)-(2 \beta-\alpha) r^{2}}\right)^{1 / 2}
$$

show that the results obtained in the theorem are sharp.

Taking $\beta=1$, in Theorem 2 , we get the following result due to McCarty [8] which also includes the result obtained by Tepper [16].

CoRollary 2(a). Each $g \in S_{a}^{*}(\alpha)$ maps $|z|<r_{0}$ onto a convex region where $r_{0}$ is the smallest positive root of the equation

$$
\begin{aligned}
1+(6 \alpha-2) a r & +\left(4 \alpha^{2} \alpha^{2}+8 \alpha-6\right) r^{2}+\left(8 \alpha^{2}-2 \alpha-2\right) a r^{3} \\
& +(2 \alpha-1)^{2} r^{4}=0
\end{aligned}
$$

if $R_{a} \geqq R^{*}$ and

$$
r_{0}=\left[(5 \alpha-1) /\left\{\left(4 \alpha^{2}-\alpha+1\right)+4 \alpha \sqrt{\left.\left(\alpha^{2}-3 \alpha+2\right)\right\}}\right]^{1 / 2}\right.
$$

if $R_{a} \leqq R^{*}$ where

$$
R_{a}=\frac{1+2 \alpha a r+(2 \alpha-1) r^{2}}{1+2 \alpha r+r^{2}}, R^{*}=\left(\frac{\alpha(1-(2 \alpha-1)) r^{2}}{(2-\alpha)\left(1-r^{2}\right)}\right)^{1 / 2}
$$

and $r=|z|<1$. The result is sharp for each $\alpha(0 \leqq \alpha<1)$ and $0 \leqq a \leqq 1$. 
REMARKS. (i ) Replacing $(\alpha, \beta)$ by $(0,1 / 2)$, or by $(0,(2 \delta-1) /$ $2 \delta), 1 / 2<\delta \leqq 1$, or by $((1-\gamma) / 1+\gamma,(1+\gamma) / 2), 0<\gamma \leqq 1$, we may obtain the estimates for the radii of convexity for functions with flxed second coefficient of the classes introduced and studied by Eenigenburg [2], Ram Singh [14] and Padmanabhan [10] respectively.

(ii) Setting $a=1$ in Theorem 1 and Theorem 2 we get the sharp estimates for the radii of convexity for functions in $R(\alpha, \beta)$ and $S^{*}(\alpha, \beta)$. These were obtained by the authors in [9] and [5] and thus also include the results obtained in [1], [2], [13] etc.

( iii ) By setting $a=0$ in Theorem 1 and Theorem 2, we may get the results for functions in $R(\alpha, \beta)$ and $S^{*}(\alpha, \beta)$ with missing second coefficient and in particular for odd functions in these classes.

The authors wish to thank the referee for his helpful suggestions.

\section{REFERENCES}

1. T. R. Caplinger and W. M. Causey, A class of univalent functions, Proc. Amer. Math. Soc., 39 (1973), 357-361.

2. P. J. Eenigenburg, A class of starlike mappings in the unit disc, Compositio Math., 24 (1972), 235-238.

3. R. M. Goel, A class of univalent functions whose derivatives have positive real part in the unit disc, Nieuw Arch. Wisk., 15 (1967), 55-63.

4. - A class of univalent functions with fixed second coefficients, J. Math. Sci., 4 (1969), 85-92.

5. O. P. Juneja and M. L. Mogra, On starlike functions of order $\alpha$ and type $\beta$, Rev. Roumaine Math. Pures Appl., 23 (1978), 751-765.

6. — A class of univalent functions, Bull. Sci. Math., (To appear).

7. T. H. MacGregor, Functions whose derivatives have positive real part, Trans. Amer. Math. Soc., 104 (1962), 532-537.

8. C. P. McCarty, Two radius of convexity problems, Proc. Amer. Math. Soc., 42 (1974). 153-160.

9. M. L. Mogra, On a class of univalent functions whose derivatives have a positive real part, (Communicated).

10. K. S. Padmanabhan, On certain classes of starlike functions in the unit disc, J. Indian Math. Soc., 32 (1968), 89-103.

11. M. S. Robertson, Variational methods for functions with positive real part, Trans. Amer. Math. Soc., 102 (1962), 82-93.

12. - Extremal problems for analytic functions with positive real part and applications, Trans. Amer. Math. Soc., 106 (1963), 236-253.

13. D. B. Shaffer, Distortion theorems for a special class of analytic functions, Proc. Amer. Math. Soc., 39 (1973), 281-287.

14. R. Singh, On a class of starlike functions II, Ganita, 19 (1968), 103-110.

15. V. Singh and R. M. Goel, On radii of convexity and starlikeness of some classes of functions, J. Math. Soc. Japan, 23 (1971), 323-339.

16. D. E. Tepper, On the radius of convexity and boundary distortion of schlicht functions, Trans. Amer. Math. Soc., 150 (1970), 519-528.

Received September 26, 1977 and in revised form March 17, 1978. 


\title{
PACIFIC JOURNAL OF MATHEMATICS
}

\section{EDITORS}

RICHARD ARENS (Managing Editor)

University of California

Los Angeles, CA 90024

Charles W. Curtis

University of Oregon

Eugene, OR 97403

C. C. MOORE

University of California

Berkeley, CA 94720

\section{J. DUGUNDJI}

Department of Mathematics University of Southern California Los Angeles, CA 90007

R. Finn and J. Milgram

Stanford University

Stanford, CA 94305

\section{ASSOCIATE EDITORS}
E. F. BECKENBACH
B. H. NeumanN
F. WOLF
K. YOSHIDA

\section{SUPPORTING INSTITUTIONS}

\author{
UNIVERSITY OF BRITISH COLUMBIA \\ CALIFORNIA INSTITUTE OF TECHNOLOGY \\ UNIVERSITY OF CALIFORNIA \\ MONTANA STATE UNIVERSITY \\ UNIVERSITY OF NEVADA, RENO \\ NEW MEXICO STATE UNIVERSITY \\ OREGON STATE UNIVERSITY \\ UNIVERSITY OF OREGON
}

\author{
UNIVERSITY OF SOUTHERN CALIFORNIA \\ STANFORD UNIVERSITY \\ UNIVERSITY OF HAWAII \\ UNIVERSITY OF TOKYO \\ UNIVERSITY OF UTAH \\ WASHINGTON STATE UNIVERSITY \\ UNIVERSITY OF WASHINGTON
}

The Supporting Institutions listed above contribute to the cost of publication of this Journal, but they are not owners or publishers and have no responsibility for its content or policies.

Mathematical papers intended for publication in the Pacific Journal of Mathematics should be in typed form or offset-reproduced, (not dittoed), double spaced with large margins. Please do not use built up fractions in the text of the manuscript. However, you may use them in the displayed equations. Underline Greek letters in red, German in green, and script in blue. The first paragraph or two must be capable of being used separately as a synopsis of the entire paper. Items of the bibliography should not be cited there unless absolutely necessary, in which case they must be identified by author and journal, rather than by item number. Manuscripts, in triplicate, may be sent to any one of the editors. Please classify according to the scheme of Math. Reviews, Index to Vol. 39. All other communications should be addressed to the managing editor, or Elaine Barth, University of California, Los Angeles, California, 90024.

50 reprints to each author are provided free for each article, only if page charges have been substantially paid. Additional copies may be obtained at cost in multiples of 50 .

The Pacific Journal of Mathematics is issued monthly as of January 1966. Regular subscription rate: $\$ 72.00$ a year (6 Vols., 12 issues). Special rate: $\$ 36.00$ a year to individual members of supporting institutions.

Subscriptions, orders for numbers issued in the last three calendar years, and changes of address should be sent to Pacific Journal of Mathematics, P.O. Box 969, Carmel Valley, CA 93924, U.S.A. Older back numbers obtainable from Kraus Periodicals Co., Route 100, Millwood, NY 10546.

PUBLISHED BY PACIFIC JOURNAL OF MATHEMATICS, A NON-PROFIT CORPORATION

Printed at Kokusai Bunken Insatsusha (International Academic Printing Co., Ltd.). 8-8, 3-chome, Takadanobaba, Shinjuku-ku, Tokyo 160, Japan.

Copyright (C) 1978 by Pacific Journal of Mathematics Manufactured and first issued in Japan 


\section{Pacific Journal of Mathematics \\ Vol. 78, No. $2 \quad$ April, 1978}

Su-Shing Chen, Weak rigidity of compact negatively curved manifolds .... 273

Heinz Otto Cordes and D. A. Williams, An algebra of pseudodifferential operators with nonsmooth symbol ....................... 279

Herbert Paul Halpern, Normal expectations and integral decomposition of type III von Neumann algebras ......................... 291

G. Hochschild, On representing analytic groups with their

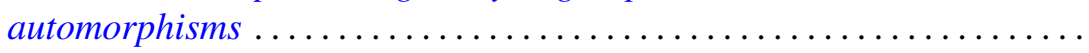

Dean G. Hoffman and David Anthony Klarner, Sets of integers closed under affine operators - the closure of finite sets ....................

Simeon Ivanov, On holomorphic relative inverses of operator-valued

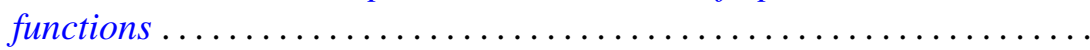

O. P. Juneja and M. L. Mogra, Radii of convexity for certain classes of

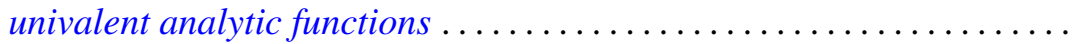

Hadi Kharaghani, The evolution of bounded linear functionals with application to invariant means.......................... 369

Jack W. Macki, A singular nonlinear boundary value problem .......... 375

A. W. Mason and Walter Wilson Stothers, Remarks on a theorem of $L$. Greenberg on the modular group ........................ 385

Kevin Mor McCrimmon, Peirce ideals in Jordan algebras . . . . . . . . . . . 397

John C. Morgan, II, On the absolute Baire property ................ 415

Gerard J. Murphy, Commutative non-Archimedean $C^{*}$-algebras ...

Masafumi Okumura, Submanifolds with L-flat normal connection of the

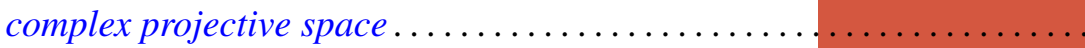

Chull Park and David Lee Skoug, Distribution estimates of barrier-crossing probabilities of the Yeh-Wiener process ...............

Irving Reiner, Invariants of integral representations ........

Phillip Schultz, The typeset and cotypeset of a rank 2 abelian group ..... 503

John Brendan Sullivan, Representations of Witt groups ....

Chia-Chi Tung, Equidistribution theory in higher dimensions . . . 